\title{
COR PULMONALE FROM REPEATED PULMONARY EMBOLISM
}

\author{
By NeIl A. J. HAMER, M.B., M.R.C.P. \\ Registrar, National Heart Hospital, London
}

\section{Introduction}

Though Virchow ( $185^{6}$ ) recognized that antemortem clots in the pulmonary arteries were usually due to emboli, for many years thrombosis in situ was regarded as more frequent. Belt (r939a) showed conclusively that pulmonary infarction was due to embolism in the majority of cases, and usually originated in phlebothrombosis in the lower limbs or pelvis. Thrombosis frequently complicates embolism, and may also occur on local lesions of the pulmonary arteries. In longstanding cases when the clot is partly organized an underlying embolus is difficult to identify.

Both thrombosis and embolism in the pulmonary arteries are frequent complications of pulmonary hypertension. Atheromatous plaques in the pulmonary arteries may be the site of thrombosis, and the low cardiac output favours thrombosis in the leg veins which gives rise to emboli.

Immobilization is an important factor reducing venous flow and producing phlebothrombosis in the legs or pelvis after surgical operations and in the puerperium. Pulmonary emboli frequently arise from these thrombi, and may complicate thrombophlebitis in varicose veins or following injury or infection.

The effects of a pulmonary embolus depend on the size of the vessel which is blocked. In the smaller arteries no change in the lung can be detected, but in a larger vessel occlusion is followed by infarction of the lung distal to the obstruction. Emboli in the main pulmonary arteries do not produce striking effects unless more than twothirds of the pulmonary circulation is blocked. There may be transient faintness, dyspnoea, dry cough, or a sense of tightness in the chest. Some patients show a temporary rise in systemic venous pressure (Wood, 1956). When obstruction to the pulmonary blood flow exceeds the critical level there is a sudden fall of cardiac output producing the clinical picture of acute cor pulmonale. These patients often die within a few days, but survivors show right ventricular failure which gradually resolves, though recurrence is frequent.

The clinical evidence of repeated pulmonary embolism thus varies greatly. There may be dramatic major attacks or transient symptoms of doubtful significance. Some episodes are completely silent. Attacks of pulmonary infarction with pleuritic pain and haemoptyses are frequent and may be mistakenly diagnosed as pneumonia (Evans, 1956).

Each pulmonary embolus is quickly impacted in the pulmonary arterial tree and becomes reduced in size, so decreasing the obstruction to blood flow. In some patients after repeated pulmonary embolism the pulmonary artery pressure becomes permanently raised. Unless some other mechanism is operating, this implies that recurrent embolism or secondary thrombosis is continuing throughout the course of the disease. Wood (1956) suggests that in a proportion of subjects a rise in pulmonary artery pressure, whatever the cause, initiates vasoconstriction in the pulmonary vascular bed. The raised pulmonary artery pressure itself produces intimal proliferation in the smaller vessels which also tends to increase the obstruction. These changes are probably responsible for the sustained pulmonary hypertension that may follow repeated pulmonary embolism.

These patients present with evidence of pulmonary hypertension in the absence of other cardiac or parenchymal lung disease, and if untreated progressively deteriorate and die with intractable right ventricular failure.

\section{Incidence}

Cor pulmonale following repeated pulmonary embolism was first described by Ljungdahl (I928). McKeown (1952) studied I I I cases of cor pulmonale at autopsy and found five of this type. In the same series there were eight cases of pulmonary arteritis or unexplained pulmonary hypertension.

In review of the literature 42 cases were found 
that had survived more than three months from the onset of symptoms. The average duration of the illness was $2 \frac{1}{2}$ years, and the longest survival 17 years (Owen et al., 1953). There was no difference in incidence between the sexes, and the age at death ranged from 22 to 73 years. One third of the patients died before the age of 40 years.

In most cases the emboli were derived from thrombosis in the veins of the lower limb. One case was due to the pressure of a truss on the femoral vein (Davison et al., 1956), and in another thrombophlebitis followed an infection in the hand. Mantz and Craige (I95I) report an unusual patient with emboli from a thrombosis of the portal vein. In two of the cases described by Owen et al. (1953), the emboli arose within the heart. In four patients the onset was related to a pregnancy.

\section{Symptoms and their Mechanism}

The effect of pulmonary vascular obstruction is to limit the pulmonary blood flow, and this results in a similar restriction of the systemic flow. In the early stages this limitation is important only when the body needs a high cardiac output, as on exertion. Dyspnoea, syncope and angina pectoris are produced on effort. Fatigue may be the dominant feature as in other conditions with a restricted cardiac output, and is liable to be mistaken for a neurotic symptom. Angina pectoris occurs in the absence of coronary artery disease, and is probably due to the inadequate coronary blood flow on effort which fails to supply the metabolic demands of the left ventricular myocardium (Stuckey, 1955). Syncope on effort is also related to the restricted cardiac output which produces cerebral hypoxia. Howarth and Lowe (1953) found that the steep rise in the pulmonary artery pressure on exertion produced transient right ventricular failure with a fall in cardiac output. These episodes may culminate in epileptic fits. Ball et al. (1956) found restlessness a prominent feature in the late stages, and this may result from the impaired cerebral blood flow.

As the disease progresses the cardiac output becomes more limited until it is below the normal resting level and can increase very little on exercise. Dyspnoea becomes progressively more severe and is eventually present at rest.

The mechanism of dyspnoea in this disease is obscure. There is no evidence of raised pulmonary venous or capillary pressures, or of increased stiffness of the lungs as is found in left ventricular failure or mitral stenosis. Pulmonary function tests are normal (Davison et al., 1956), though the ventilatory cost of exercise is increased. This enables these patients to be distinguished from those with pulmonary hypertension due to emphysema or other parenchymal lung disease. In pulmonary hypertension due to repeated embolism the dyspnoea closely resembles hyperventilation, $\stackrel{\mathbb{Q}}{\complement}$ and paroxysms of air hunger may occur (Belt, $\subseteq$ I939b). This overbreathing is probably a re- $\overrightarrow{\vec{D}}$ sponse to the reduced supply of oxygen to the tissues as a result of the impaired cardiac output. Orthopnoea is often reported in these patients (Carroll, 1950; Magidson and Jacobson, 1955), but may imply only that hyperventilation is better tolerated in the upright position.

Hoarseness has been described as an early $\overrightarrow{0}$ symptom (Mantz and Craige, I95I), and attributed $\overrightarrow{-}$ to pressure from the large pulmonary artery on $\vec{\omega}$ the left recurrent larygeal nerve.

\section{Physical Signs}

The restricted cardiac output in pulmonary $\stackrel{\omega}{\oplus}$ hypertension produces a small pulse and cold pale $\underset{\infty}{\omega}$ extremities. There may be a malar flush. These? signs are sometimes obscured by vasodilatation due to liver damage from congestive heart failure. This produces warm extremities with palmar erythema and dilated forearm veins.

Cyanosis is a frequent finding, and is usually peripheral in origin. Central cyanosis is not infrequent, however, and there may be fingeg $\vec{c}$ clubbing. Harvey et al. (195I) investigated of patient with an arterial oxygen saturation \& 86 per cent., which fell to 55 per cent. on efforte In some cases the cyanosis is due to the development of a right to left shunt through a patent foramen ovale as the filling resistance of the right ventricle rises (Magidson and Jacobson, 1955). In other cases cyanosis may be due to bronchial collateral vessels draining into the pulmonary veins (Means and Mallory, I93 I), or angiomatous bypasses in the lungs similar to those described by Bedford et al. (1946) in pulmonary schistosomiasis. Castleman and Bland (1946) describe a patient with cyanosis early in the course of the disease, in whom large subpleural collateral vessels were found at autopsy.

Some central cyanosis may be expected in the absence of abnormal vascular communications when the cardiac output is greatly reduced. In $\frac{D}{0}$ conditions with a small pulmonary blood flow the normal venous admixture from perfusion of under- $N$ ventilated alveoli or from bronchial veins will have a greater effect than usual on the arterial oxygen saturation.

Polycythaemia is frequent in patients with central cyanosis, and Barnard (1954b) suggests $\stackrel{0}{=}$ that the increased blood viscosity which results $\mathscr{D}$ may accentuate the resistance to blood flow in the lungs.

Pulmonary hypertension produces right ventricular hypertrophy, evidenced by a palpable thrust $\frac{?}{\mathbb{D}}$ to the left of the sternum, and electrocardiographic 
changes, of which the most important is the appearance of a dominant $R$ wave in the right chest leads and in lead aVR. Pulsation of the pulmonary artery can be felt in the second left intercostal space. A pulmonary systolic ejection click usually precedes a soft ejection systolic murmur in the pulmonary area. The pulmonary component of the second sound is accentuated, and is less clearly separated from the aortic component than normally. Both the ejection click and the pulmonary second sound are often palpable. An immediate diastolic murmur of pulmonary incompetence may follow the second sound.

The presence of an embolus or thrombus in the main pulmonary artery may modify these signs. If the clot extends to the pulmonary valve, the pulmonary second sound may be soft (Ball et al., I956) or natural (Evans, I956). A loud pulmonary systolic murmur with a thrill may be produced by the obstruction and has led to a diagnosis of congenital heart disease (Magidson and Jacobson, 1955). In some cases a to-and-fro murmur has been reported from a partially obstructed pulmonary artery (Carroll, I950).

Right ventricular hypertrophy increases the resistance to filling of the right ventricle. This produces increased right atrial activity, as evidenced by a dominant ' $a$ ' wave in the jugular venous pulse, presystolic hepatic pulsation, a presystolic sound at the left sternal edge, and evidence of right atrial hypertrophy in the electrocardiogram.

In the later stages right ventricular failure dominates the clinical picture, though normal rhythm is usually maintained (Owen et al., 1953). The increased venous pulsation in the neck may be obvious to the patient, and this may be useful in determining the duration of failure. Right ventricular failure is often complicated by tricuspid incompetence which produces a pan-systolic murmur at the left sternal edge that may increase in intensity on inspiration. A systolic wave replaces the ' $x$ ' descent in the jugular venous pulse in these cases.

\section{Radiological Findings}

Hanelin and Eyler (195I) give a full description of the X-ray appearances in these patients. The periphery of the lung is relatively clear as the vascular markings distal to the obstruction are reduced in size. The main pulmonary arteries are dilated and form prominent hilar shadows. The same appearance is produced if the main vessels are packed with clot or if they are dilated proximal to multiple obstructions in the smaller pulmonary arteries. Evidence of pulmonary infarction as described by Short (195I) is frequent. There is usually evidence of enlargement of the right atrium and ventricle.

Screening shows that pulsation is reduced in the dilated main pulmonary arteries (Ball et al., 1956).

\section{Pathology}

The lesions in the pulmonary arterial tree may be confined to the smaller branches, or obstructions may be present in the larger vessels (Barnard, 1954b). Emboli in the main branches of the pulmonary artery are usually associated with multiple occlusions in the smaller vessels. These may result from fragmentation of a large embolus (Owen et al., 1953). In some patients, however, lesions are found only in the main pulmonary arteries (Petch, I95I).

Thirty-two case reports were reviewed in which there was evidence of the level of obstruction in the pulmonary arterial tree. In 22 of these cases the main pulmonary arteries were involved. The average duration of the illness was 3 years $I$ month in this group, but only I year 3 months in those with obstruction in the smaller vessels only.

Only the outer parts of large emboli become organized; the deeper parts undergo hyaline changes. Smaller emboli are completely replaced by collagenous and elastic tissue, and are permeated by new vascular channels (Owen et al., 1953). These lesions closely resemble organized thrombi. Many vessels show fibrous intimal thickening which is probably secondary to the raised pulmonary artery pressure. Castleman and Bland (1946) report a patient with multiple obstructions in the tertiary pulmonary artery branches. The vessels proximal to the obstruction showed intimal thickening and atheroma, while the distal vessels were thin-walled and atrophic.

The lesions in the smaller pulmonary arteries produced by repeated embolism closely resemble those found in some cases of 'primary' or ' solitary' pulmonary hypertension (Evans et al., I957). Similar changes have been produced by the repeated intravenous injection of fragmented blood clot in animals (Harrison, I 948; Wartman et al., 1951; Barnard, 1954b). East (1950) and McKeown (1952) describe cases of 'prinary' et al., I95 I Barnard, I954b). East (1950) and McKeown (1952) describe cases of 'primary" pulmonary hypertension with almost normal pulmonary vessels, but most cases show extensive intimal proliferation in the smaller arteries. The demonstration of multiple defects in the media of the pulmonary arteries by Gilmour and Evans (1946) is not conclusive evidence of a congenital abnormality as similar defects are seen over the 
intimal lesions produced by injections of blood clot in animals (Barnard, 1954b).

The distinction of pulmonary hypertension due to repeated emboli in which the lesions are confined to the smaller arteries from 'primary' pulmonary hypertension relies on the demonstration of a possible source of emboli (Evans, 1956). An association with pregnancy, or the demonstration of extensive thrombosis in the pulmonary arteries, favours an embolic origin (Wood, 1956).

\section{Coagulation Disturbances}

Many authors have suggested that an increased coagulability of the blood is responsible for repeated pulmonary embolism. Abnormalities of the coagulation mechanism have been demonstrated in conditions usually associated with venous thrombosis, for instance after operations and in the puerperium. Wright (1942) showed that platelet stickiness was increased, and Wessler et al. (1956) found an increase in factor VII activity in these situations.

Barnard (1954a) produced lesions in the pulmonary arteries of animals by repeated intravenous injections of purified thromboplastin. The changes resembled those which followed repeated injections of blood clot. He suggests that intravascular coagulation is more common than is usually thought. Any coagulation in the blood stream would be self-limited as fibrin itself has potent antithrombin activity. However, Sternberger (1952) has demonstrated thrombin in the circulating blood, which suggests that some coagulation is occurring despite the presence of normal anticoagulants such as heparin.

It seems possible that obstructive lesions in the smailer pulmonary arteries may follow the intravascular formation of fibrin without macroscopic thrombosis. This would provide a link between the embolic and the 'primary' forms of pulmonary hypertension.

\section{Tumour Embolism}

Acute cor pulmonale may follow emboli of air, fat or amniotic fluid, but survivors recover rapidly. A few patients with carcinoma of the stomach or breast develop subacute cor pulmonale due to obstruction of the pulmonary vessels by tumour emboli. Most cases are associated with lymphangitis carcinomatosa, but Brill and Robertson (1937) describe a case with no lymphatic or parenchymal involvement of the lungs.

Morgan (1949) reviewed 4o cases of arteriolar obstruction in lymphangitis carcinomatosa and found tumour emboli responsible in ten. In the other cases the obstruction was thought to be due to organized thrombus secondary to subendothelial lymphatic permeation. Many of the cases re- ported have been slow-growing scirrhus tumours. The longest survival is five years in a case reported by McKeown (1952) due to a chorionepithelioma which later became arrested.

\section{Differential Diagnosis}

Pulmonary hypertension due to repeated embolism must be distinguished from pulmonary hypertension secondary to other disorders. The position is complicated by the frequent occurrence of pulmonary embolism as a complication of pulmonary hypertension of any cause.

Pulmonary vascular obstruction in chronic parenchymal lung disease is distinguished by the presence of abnormal pulmonary function tests. Most of these cases are due to emphysema and have an abnormally high arterial $\mathrm{pCO}_{2}$. Pulmonary schistosomiasis is suggested by a story of residence in an endemic area.

Mitral stenosis causing pulmonary hypertension can usually be recognized by the presence of a mitral diastolic murmur and an opening snap, but in some cases these are difficult to detect. The $\mathrm{X}$-ray shows left atrial enlargement however, and calcification of the mitral valve may be seen.

Pulmonary hypertension complicating a septal defect or patent ductus arteriosus may cause difficulty, especially as cyanosis and a loud basak systolic murmur may occur in cases due tô repeated embolism. Cardiac catheterization is of value in distinguishing these lesions, and also enables the severity of the pulmonary hypertension to be measured.

The diagnosis of ' primary' pulmonary hypertension has already been discussed. The detection of episodes suggesting thrombophlebitis or pulmonary infarction is important. There may be a story of oedema or a tender spot on one ankle (Evans, 1956). Haemoptyses and pleuritic pain are frequent.

Early diagnosis is important in these patients as it has been shown that intensive treatment can be effective. The early symptoms of pulmonary vascular obstruction are difficult to assess, and diagnosis at this stage relies mainly on the detection of the physical signs of pulmonary hypertension.

\section{Therapy}

Treatment must be directed to the reduction of the pulmonary artery pressure and the prevention of further emboli. Any obvious cause of phlebothrombosis must be treated and venous stasis discouraged. Evans (1956) and Petch (195I) recommend ligation of the main veins in the groin or at a higher level to prevent further emboli. Anticoagulant therapy will tend to prevent further thrombosis in the leg veins or in the pulmonary arteries, and should certainly be commenced 
immediately a pulmonary embolus is recognized. Wessler et al. (1956) suggest that heparin is superior to drugs of the coumarin or indanedione group in preventing thrombosis, but it cannot be used for long-term therapy. At present the best drug for prolonged therapy is phenylindanedione (dindevan). Occasional patients are allergic to dindevan, and a suitable alternative is sinthrome which has a similar duration of action. Anticoagulant therapy is needed for many months or even years in these patients. Wood (1956) describes three patients surviving after prolonged anticoagulant therapy, one of whom showed a return to normal findings at catheterization. Davison et al. (1956) also report a patient in whom the progress of the disease appeared to have been arrested by anticoagulant treatment.

Wood (1956) stresses the value of prolonged bed rest in this condition. Any effort causes a rise in pulmonary artery pressure which may cause secondary proliferative changes in the smaller vessels or further pulmonary vasoconstriction. No beneficial effect has been demonstrated with cortisone and its derivatives, or with vasodilator drugs. Aminophylline or priscoline may be tried as they are the agents most likely to reduce the pulmonary artery pressure when taken by mouth.

\section{Conclusions and Summary}

Repeated pulmonary embolism may cause sustained pulmonary hypertension. When large emboli in the main pulmonary arteries are responsible the prognosis is somewhat better than in those with multiple emboli in the smaller vessels. Prolonged treatment with rest and anticoagulants is of value.

Those with multiple obstructions in the small pulmonary arteries closely resemble the patients described as ' primary' pulmonary hypertension, and the cause of the pulmonary vascular obstruction may be similar in the two conditions.

\section{BIBLIOGRAPHY}

BALL, K. P., GOODWIN, J. F., and HARRISON, C. V. (I956), Circulation, 14, 766.

BARNARD, P. J. (1954a), Brit. Heart F., 16, 93.

BARNARD, P. J. (1954b), Circulation, 10, 343 .

BEDFORD, D. E., AIDAROS, S. M., and (;IRGIS, B. (1948), Brit. Heart $\mathcal{F} ., 8,87$.

BELT, T. H. (1939a), Itid., r, 283

BELT, T. H. (1939b), Lancet, ii, 730 .

BRILL, I. C., and ROBERTSON, T. D. (1937), Arch. intern. Med., 60 , 1043

CARROLL, D. (1950), Amer. F. Med., 9, 175.

CASTLEMAN, B., and BLAND, E. F. (1946), Arch. Path., 42, 58 I.

DAVISON, P. H., ARMITAGE, G. H., and McILVEEN, D. J. S. (1956), Lancet, ii, 224.

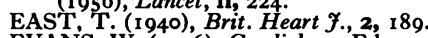

EVANS, W. (1956), Cardiology, Ed. 2.

EVANS, W., SHORT, D. S., and BEDFORD, D. E. (1957),

Brit. Heart $\mathcal{F}$., 19, 93 .
GILMOUR, J. R., and EVANS, W. (1946), f. Path. Bact., 58, 687

HANELIN, J., and EYLER, W. R. (I95I), Radiology, 56, 689.

HARRISON, C. V. (1948), \%. Path. Bact., 60, 289.

HARVEY, R. M., FERRER, M. I., RICHARDS, D. W., and COURNAND, A. (195I), Amer. F. Med., 10, 719 .

HOWARTH. S., and LOWE, J. B. (1953), Brit. Heart $\dot{\mathcal{Y}}$., 15, 47.

LJUNGDAHL, M. (1928), cited by Friedberg, C. K. (1956), 'Diseases of the Heart, 'Ed. 2 .

McKEOWN, F. (1952), Brit. Heart $\dot{\mathcal{F}}$., 14, 25.

MAGIDSON, O., and JACOBSON, G. (1955), Ibid., 17, 207.

MANTZ, F. A., and CRAIGE, E.'(1951), Arch. Path., 52, 91.

MEANS, J. H., and MALLORY, T. B. (1931), Ann. intern. Med., MORGAIN,

OWEN, W. R., THOMAS, W. A., CASTLEMAN, B., and BLAND, E.' F. (1953), New Engl. F. Med., 249, 9ro.

PETCH, C. P. (195I), Lancet, $i, 346$.

SHORT, D. S. (I95I), Quart. $尹$. Med., 20, 233.

STERNBERGER, L. A. (1952), $\mathcal{F}$. Amer. med. Ass., 150, 1591.

STUCKEY, D. (1955), Brit. Heart f., 17, 397.

VIRCHOW, R. (1856), cited by Belt, T. H. (1939a), Jbil1,., 283.

WARTMAN, W. B., JENNINGS, R. B., and HUDSON, B.' (1951),

Circulation, 4, 747.
WESSLER, S., COHEN, S., and FLEISCHNER, F. G. (1956), New Engl.' F. Med., 254, 413 .

WOOD, P. (1956), 'Diseases of the Heart and Circulation', Ed. 2. WRIGH', H. P. (1942), Ұ. Path. Bact., 54, 461 .

\section{HEPATIC DISEASE}

(Postgraduate Medical Journal)

Price: 3s. 9d. post free

\section{JAUNDICE}

Sheila Sherlock, M.D., M.R.C.P.

HEPATIC COMA

J. M. Walshe, M.A., M.R.C.P.

SURGICAL TREATMENT OF PORTAL HYPERTENSION

A. l. S. Macpherson, Ch M., F.R.C.S.E.

WILSON'S DISEASE

A. G. Bearn, M.D.
ASCITES IN LIVER DISEASE

Michael Atkinson, M.D. (Lond.)

M.R.C.P.

\section{PSYCHIATRIC ASPECTS OF LIVER} DISEASE

Esther A. Davidson, M.R.C.P.Ed., and

W. H. J. Summerskill, M.A., M.R.C.P.

\author{
PERCUTANEOUS PORTAL \\ VENOGRAPHY \\ David Sutton, M.D., M.R.C.P., F.F.R.
}

